\title{
Can Greek Learners Acquire the Overt Subject Property of English? A Pilot Study
}

\author{
Alexandra I. Prentza \\ Department of Business Administration, Technological Educational Institute of Epirus, Greece \& Aristotle University \\ of Thessaloniki, Greece
}

\begin{abstract}
This paper reports the results of the pilot part of a wider study exploring the second language (L2) grammars of beginner, intermediate and advanced Greek learners of English. The experiment considers the acceptability of structures with null and postverbal subjects, as well as the acceptability of permutations inducing that- $t$ violations in L2 English. The results have suggested that there is a developmental trend with increasing proficiency with the more proficient groups exhibiting improved performance. However, it was found that $\mathrm{L} 2$ performance does not reach native standards, since the advanced group fared significantly less successfully than the English control group in all the structures tested. This data lends empirical support to recent theoretical proposals that cross-linguistic differences between $\mathrm{L1}$ and $\mathrm{L} 2$ in the form of syntactic feature mismatch can cause prolonged learnability problems which are difficult, if not impossible, to overcome.
\end{abstract}

Index Terms - second language acquisition, null subjects, postverbal subjects, that-t violations, syntactic features

\section{INTRODUCTION}

Researchers within the field of Second Language Acquisition (SLA) have always attempted to address the question of whether adult L2 performance can be native-like and, if this is not feasible, what are the possible reasons. Recently, within minimalism (Chomsky, 1995; 2001), learner unsuccessful performance has been associated with a difference between L1 and L2 syntactic features. In very simple terms, researches endorsing the above view propose that in areas where L1 and L2 differ with respect to syntactic features, i.e. in areas where there is syntactic mismatch between L1 and L2, adult L2 learners are expected to encounter insuperable acquisitional problems. Due to maturational constraints, L2 syntactic features are not available to adult learners, i.e. adult learners cannot use them to analyze the L2 input (Tsimpli \& Mastropavlou, 2007). Thus, ultimate attainment of the targeted structures is assumed to be impossible (see for earlier accounts Beck, 1998; Hawkins \& Chan, 1997; Tsimpli \& Roussou, 1991 and for more recent accounts Hawkins \& Hattori, 2006; Tsimpli \& Dimitrakopoulou, 2007 (the Interpretability Hypothesis). For studies supporting these accounts see Prentza, 2010, 2014; 2014; Prentza \& Tsimpli, 2013a, b). Note crucially that semantic features like [referentiality] on nouns and pronouns which contribute to the semantic interpretation of syntactic expressions are, by assumption, not subjected to a critical period and are thus more readily available to adult learners (Prentza, 2010; Prentza \& Tsimpli, 2013a; Tsimpli \& Mastropavlou, 2007).

L1 Greek and L2 English differ in the syntactic properties which are considered to follow from the fact that Greek is a null-subject language (NSL) but English is not. The properties traditionally related with the positive setting of the Null Subject Parameter (Rizzi, 1982; 1986) instantiated by Greek are the availability of null and postverbal configurations as well as the absence of that- $t$ violations. With this given, the study presented here, which constitutes the pilot part of a wider experiment (see Prentza, 2010; Prentza and Tsimpli 2013a), aims to test the hypothesis that syntactic divergence, as this is defined by syntactic feature mismatch, will lead to L2 performance which will deviate from the native norm at all times.

This paper is organized as follows: Section 2 provides the theoretical framework of the study. It analyzes the relevant differences between L1 Greek and L2 English, provides an overview of previous L2 findings and outlines the predictions formulated for this study. Section 3 presents the experiment and the obtained data and finally, Section 4 discusses the results and their implications.

\section{THEORETICAL FRAMEWORK}

\section{A. Syntactic Differences between L1 Greek and L2 English}

Research in theoretical linguistics within the generative framework has proposed that the syntactic differences between languages like Greek and languages like English are related to the nature of verbal agreement morphology in the former: Greek exhibits rich agreement inflection on the verb comprising a full person/number paradigm in all tenses, while English does not. From that follows the availability of null and postverbal subjects (see originally Taraldsen, 1979; Rizzi, 1982 and more recently, Alexiadou \& Anagnostopoulou, 1998; Barbosa, 1995; 2000; 2009; Kato, 1999; Platzack, 2004; Roussou and Tsimpli, 2006; Spyropoulos \& Philippaki-Warburton, 2001 among others). More recently the lack 
of that- $t$ violations in languages like Greek (i.e. the possibility of extracting the subject across an overt complementizer like that) has also been related to the nature of subject-verb agreement in Greek (see Roussou, 2002; Tsimpli \& Dimitrakopoulou, 2007). Hence, much recent linguistic theory attributes the aforementioned differences in the Null Subject Parameter properties to a divergence in the abstract syntactic features of verbal agreement of the languages involved. Let us now present in more detail the properties under question.

Greek being a NSL, allows null referential (i.e. lexical) subjects in both matrix and subordinate clauses on the one hand, and, requires null expletive subjects in the same structures on the other, as the gloss (1) illustrates. Moreover, it exhibits subject verb inversion irrespective of predicate type (see examples in 2) and allows subject extraction out of a complement clause in the presence of the lexical complementizer oti ('that') (see examples in 3). English by contrast, requires that the subject (referential or expletive) is overtly realised, disallows postverbal subject permutations ${ }^{1}$ and permits subject extraction only in the case that the lexical complementizer that is absent or, otherwise, violations of the that- $t$ filter, i.e. that- $t$ violations are induced. Notice however that object extraction across an overt complementizer is a licit option in English:

(1)__ Ipan oti_tha xionisi (null referential \& expletive subject)

Said.3PL that will snow.3SG

*(they) said that *(it) will snow

'They said that it will rain'

(2) a. Eftase/Jelase i Anna arrived.3SG /Laughed.3SG the.NOM Anna.NOM

(unaccusative/unergative)

*Arrived/ Laughed Anna

'Anna arrived/laughed'

(2) b. Etimase (to proino) o Pertos (to proino) (transitive) prepared.3SG (the.ACC breakfast.ACC) the.NOM Peter.NOM (the.ACC breakfast.ACC) *Prepared the (breakfast) Peter (the breakfast)

'Peter prepared breakfast'

(3) a. Pjos ipes oti arostise?

Who. NOM said. 2SG that got sick. 3SG

(subject extraction)

*Who did you say that got sick?

'Who did you say got sick'?

(3) b. Pjon ipes oti ide i Anna to proi?

(object extraction)

Who.ACC said.3SG that saw.3SG the.NOM Anna.NOM in.ACC the.ACC morning. ACC?

Whom did you say (that) Anna saw in the morning?

The above constitute the structures that were used in the design of the tests items of the current experiment.

\section{B. Previous L2 Findings}

The acquisition of the properties related to the Null Subject Parameter has been the focus of much research. Both earlier and more recent studies report that syntactic divergence between L1 and L2 with respect to the aforementioned syntactic options leads to unsuccessful L2 performance. This is manifested by L1 influence in interlanguage systems in the form of transfer of the L1 syntactic properties. Due to that, in the acquisition of a NSL, speakers of NSLs appear to be more successful than speakers of non-null-subject languages (NNSLs). Conversely, speakers of NNSLs fare better in the acquisition of another NNSL than speakers of NSLs. In this section we will review L2 studies pertaining to the second case (i.e. L1 NSL, L2 NNSL), since this is related to our experiment. Earlier studies will be discussed first and more recent ones will follow.

White (1985) tested Spanish beginner, intermediate and advanced learners of English in structures involving null and postverbal subjects, as well as that $t$ violations ${ }^{2}$. The beginner group was found to accept a significant proportion of ungrammatical null subjects $(64.7 \%)$, but there was a gradual improvement in the intermediate and advanced level, with the groups allowing null subjects in $41.7 \%$ and $30.5 \%$ of the cases respectively. L2 groups were found to perform more accurately with respect to postverbal items ${ }^{3}$. Regarding that- $t$ violations, Spanish learners performed rather poorly irrespective of proficiency level. In her 1986 study, White also included Italian learners in her L2 groups. The results indicated that the Spanish and Italian learners were unsuccessful in identifying the ungrammaticality of null subject sentences and of that- $t$ violations: they accepted illicit null subjects in $39 \%$ of the cases and that- $t$ violations in $58 \%$ of the times. However, in postverbal subject structures, both groups were very accurate rejecting verb-subject (VS) L2 illicit orders at a rate of $91 \%$. Tsimpli and Roussou (1991) investigated the status of the NSP in the L2 grammars of

\footnotetext{
${ }^{1}$ English allows postverbal subject permutations only in specific registers: in there-existential structures, in cases of locative inversion (see Culicover \& Winkler, 2008) and in quotative inversion (see Collins, 1997; Collins \& Branigan, 1997).

(1) There appeared a horrific sight (there-existential)

(2) On the corner stood a tall man. (locative inversion)

(3) 'I am hungry' said Mary (quotative inversion)

${ }^{2}$ White (1985) also included French learners of Spanish in her study, but for the purposes of the present discussion we will restrict our attention to the Spanish groups.

${ }^{3}$ Although White (1985) reports some problems with an ungrammatical 'There-Verb-Subject' item (for similar results see Prentza \& Tsimpli, 2013a)
} 
intermediate and post-intermediate Greek learners of English. Greek learners were found to be quite accurate in rejecting null and postverbal subject structures. Notice however, that Greek learners accepted ungrammatical null expletive subjects in $80 \%$ of the times. This is related to the distinct acquisitional routes of expletive and referential subject also evinced in previous L2 studies. To mention some representative examples, Phinney's results (1987) showed a clear difference in the acquisition of English referential and expletive subjects by Spanish L2 learners. Expletive subjects were omitted more than referential ones: high-beginner and low-intermediate Spanish learners of English omitted expletive pronouns in $76 \%$ and $56 \%$ of the obligatory contexts respectively, whereas they omitted referential pronouns only in $13 \%$ and $6 \%$ of the cases respectively. In a later study Al-Kasey \& Pérez-Leroux (1998) reported that lower proficiency learners encountered problems with null expletive subject comprehension, but more advanced learners exhibited improved performance without however achieving accuracy rates comparable with those of the English controls. In particular, elementary and intermediate learners were inaccurate in $23.19 \%$ and in $24.02 \%$ of the cases respectively choosing an L2 illicit referential reading for the expletive it rather than a generic interpretation ${ }^{4}$. The advanced group on the other hand, exhibited non-target performance in $8.33 \%$ of the times improving towards the native norm, yet remaining distinguishable from the control group. Within feature oriented accounts, such results are ascribed to the fact that expletive subjects unlike referential ones lack semantic characteristics like [referentiality] having only grammatical features. Returning to Tsimpli and Roussou's data on English subject extraction structures, it was reported that over $95 \%$ of Greek learners failed to reject L2 that- $t$ violation sentences. Tsimpli and Roussou attributed the obtained results to the inaccessibility of the involved grammatical features in adult L2 acquisition. Prolonged problems associated with English subject extraction structures were also attested in the interlanguage of advanced Greek learners in a later study conducted by Tsimpli (1997). The results showed that Greek intermediate learners achieved the lowest accuracy rates in that- $t$ items, as expected, due to the involvement of syntactic features that differ between L1 and L2.

Turning next to more recent studies, Tsimpli \& Dimitrakopoulou (2007) tested intermediate and advanced Greek learners of English and, in line with findings from previous studies, also found L1 effects on subject extraction items even at advanced stages of development. This was manifested through the following findings: First, the lack of significant development of learner accuracy in ungrammatical subject interrogatives (INT: 63.9\%, ADV: 68.4\%) and, second, the significantly less accurate performance of advanced learners compared to the English control group in rejecting that- $t$ violations (ADV: 68.4\%, NS: 96.7\%). Tsimpli and Dimitrakopoulou ascribe their data to the unavailability of syntactic features in adult L2 acquisition. This, according to the researchers leads to a transfer of the L1 syntactic options in L2 even in advanced stages of development and causes persistent learnability problems. Finally, Lozano and Mendikoetxea (2010) examined learner corpora of Spanish upper-intermediate L2 learners of English against native English corpora in an attempt to examine L2 postverbal production. The analysis of the native and nonnative corpora showed that Spanish learners produced significantly more ungrammatical postverbal structures as opposed to English natives who were accurate at all times $(65.5 \%$ vs. $0 \%)$.

\section{Predictions}

Endorsing the proposals of formal features deficit accounts, namely that cross-linguistic differences in the form of syntactic divergence can cause prolonged learnability problems, the predictions formulated for this work are the following:

A) Development of L2 grammars: it is expected that more proficient L2 learners will be more successful than less proficient ones in rejecting ungrammatical English null, postverbal and that- $t$ structures and in producing grammatical overt preverbal subject structures and licit subject extraction structures.

B) End-state of L2 grammars: due to the involvement of formal syntactic features which results to a syntactic mismatch between L1 and L2 in the targeted areas it is expected that ADV L2 learners will not acquire the English syntactic properties related to the realization (i.e. obligatorily overt), distribution (i.e. obligatorily preverbal) and properties (non-extraction across that) of the English subject.

\section{THE EXPERIMENT}

\section{A. Participants and Materials}

The subjects of the study consisted of four groups: three groups of Greek learners $(n=30)$ and a control group of English native speakers (NS) $(n=10)$. According to their scores in the Oxford Placement Test (OPT) (Allan, 1992) learners were divided into three proficiency levels: the beginner group (BEG) $(n=10)$, the intermediate group (INT)

\footnotetext{
${ }^{4}$ (4) a. P. likes this blue kite. This is fun to fly (referential interpretation) b. P likes this blue kite. (*It) is fun to fly (generic interpretation) (Al-Kasey and Pérez-Leroux , 1998: 169)

${ }^{5}$ The subjects who scored between 85 and 134 formed the BEG group, the subjects who scored between 135-150 formed the INT group and those scoring $170<$ formed the ADV group. The participants scoring between 151-169 who would normally be categorized as post-intermediate learners were excluded from the study, as one of its aims was to test for developmental L2 differences and, to this end, the INT-ADV contrast was considered more useful.
} 
$(n=10)$, and the advanced group (ADV) $(n=10)^{6}$. All learner groups had been exposed to English in a classroom setting. The beginner group had been studying English for an average of 4.5 years, the intermediate for 6 years and the advanced for 8 years. All informants were naive to the purpose of the experiment and participation to the study was voluntary and unpaid.

The materials used were one judgement and one production task: a Paced Grammaticality Judgement Task (PGJT) and a Cloze Test (CT).

The PGJT aimed at investigating the acceptability of ungrammatical null and postverbal subject structures as well as the acceptability of structures inducing that $t$ violations. The task consisted of 186 test items interspersed with 100 filler items ${ }^{7}$ resulting in a 286-item task. Half of the test items and filler items were ungrammatical and the other half were grammatical. All the items were randomised and, due to the length of the task, were divided in two questionnaires of 143 items which were administered in two sessions. The participants saw each sentence on the screen for 5 seconds ${ }^{8}$ while, at the same time, they heard it on tape ${ }^{9}$. Participants had to indicate their judgement using a 5-point scale ranging from -2 (certainly ungrammatical) to +2 (certainly grammatical) while 0 encoded the not sure option (White et al., 1998). For the purposes of the current study ${ }^{10}$, the 5 categories of the -2 to +2 scale were conflated into the categories of target, non-target and not sure. More specifically, for a sentence judged by the control group as ungrammatical ( -1 or -2$)$ all choices made on the positive side of the scale $(+1,+2)$ were considered as non-target performance. Accordingly, when controls judged a sentence as grammatical $(+1$ or +2$)$, the choices made on the negative side of the scale $(-1,-2)$ were taken to represent target-deviant performance. The not sure category encoded by the 0 choices was excluded in the analysis. Sentences in (4-6) provide examples of null, postverbal and that- $t$ violation structures respectively and of their grammatical counterparts:

(4) a. *_Has asked me a very difficult question.

This time tomorrow I will be flying to Athens.

b. *In London rains a lot all the time.

It seems that Susan did not get the job she wanted.

(5) *Serves an English butler dinner at their house.

The client arrived on time for the appointment.

(6) *Which film did you say that was very boring?

Who did you say is visiting us next week?

(null referential subject)

(null expletive subject)

(postverbal subject)

(that- $t$ violation)

Turning next to the CT, it aimed to test the production rates of English overt subjects structures and of grammatical subject extraction structures (i.e. free of that- $t$ violations). The test consisted of 26 test and 25 filler items and had to be completed in 20 minutes. Participants were instructed to use only one word for each gap in the cases they thought it was necessary. Therefore, a zero gap was allowed, since in subject extraction structures, this would be the target answer. Sentences in (7-8) offer examples of the item types of the CT (targeted responses in italics):

(7) a....He...had followed a study plan........ (referential subject)

b. In recent years.....there...............has been a change in our attitude towards the environment. (expletive subject)

(8) Who did you say............called you?

(subject extraction)

Table 1 summarizes the item types in each of the tests used.

TABLE 1.

PGJT\& CT ITEM TYPES

\begin{tabular}{llll}
\hline Tests & Item Types & Tokens & \\
\hline PGJT & Null subjects & $20^{\mathrm{a}}$ & \\
& Postverbal subjects & 53 & \\
& that $t$ & 10 & \\
\cline { 3 - 4 } & & Total: & 83 \\
\hline CT & Null subjects & $22^{\mathrm{b}}$ & \\
& that $-t$ & 4 & 26 \\
\hline & & Total: & 26 \\
\hline
\end{tabular}

a: the test also included 83 grammatical counterparts of these items b: half of the items were expletive and half referential

Participant responses in both tests were coded as target and non-target and were submitted to statistical analysis. Pearson's Chi-Square tests were used to test for independence between the variables of Group (NS, ADV, INT, BEG) and Response. Additionally, a qualitative analysis was performed on the null subject acceptance and production rates of

\footnotetext{
${ }^{6}$ Although more subjects were tested, these numbers refer to those participants who completed all parts of the test.

${ }^{7}$ The 186 test items consisted of 166 declarative and 20 interrogative sentences (the extraction items), while the 100 filler items consisted of 40 interrogative, 30 pseudo-cleft and 30 exclamative sentences.

${ }^{8}$ This time was allocated in order to allow non-native speakers enough time to see the sentence projected on the screen and subsequently indicate their judgements on the answer sheet. The three seconds gap used in trial versions of the test did not seem enough especially for the beginner group.

${ }^{9}$ During the recording of the items care was taken so that the ungrammatical items were delivered with the same intonation as the grammatical items. For this reason, the recording was repeated and the second improved version was finally used

${ }^{10}$ For the wider study another analysis was adopted: The five categories realised by the scale were maintained because we felt that the lack of certainty captured by the intermediate choices (+1 and -1 choices) is worth investigating (see Prentza, 2010)
} 
both tasks examining performance in the expletive vs. in the referential items included. Methodologically, this was allowed since in both tests half of the subject items were referential and half were expletive (see also Table 1).

\section{B. Results}

Results will be presented in three subsections, each for the type the items fall into, namely, null, postverbal and that-t structures.

Null subjects. The analysis yielded that in both the PGJT and the CT the variable of Group had a main effect on Response (both $p$ s $<0.05$ ). This means that the advanced learners fared more successfully than intermediate ones, who in their turn were more accurate than the beginner group. As expected however, all L2 groups, and, crucially, the ADV group accepted and produced significantly more ungrammatical null subjects than the control group. In both the judgment and the production task L2 learner performance does not meet native speaker standards even at more advanced levels. Thus, according to the predictions outlined, although a developmental trend is evinced, L2 performance remains target-deviant in the rejection rates of null subjects, as well as in the production rates of overt subject permutations. Fig. 1 illustrates the relevant scores:

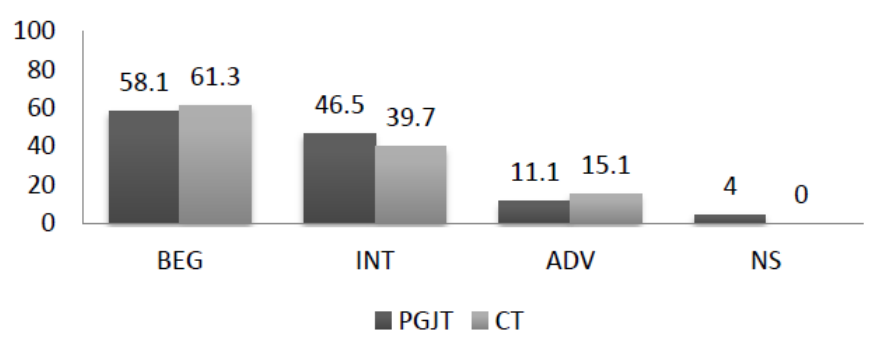

Figure 1. Non-target Performance (\%)-PGJT \& CT

Additionally, participant non-target performance illustrated in Fig.1 was subjected to a qualitative analysis whereby subject omission in referential and in expletive items was compared. Table 2 presents the relevant scores:

TABLE 2.

NON-TARGET PERFORMANCE (\%)IN EXPLETIVE VS. IN REFERENTIAL SUBJECTS -PGJT\&CT

\begin{tabular}{|c|c|c|c|c|}
\hline & \multicolumn{2}{|l|}{ PGJT } & \multicolumn{2}{|l|}{ CT } \\
\hline & Expletive & Referential & Expletive & Referential \\
\hline NS & 5 & 0 & 0 & 0 \\
\hline ADV & 16 & 7 & 22 & 10 \\
\hline INT & 57 & 40 & 44 & 35 \\
\hline BEG & 66 & 48 & 62 & 60 \\
\hline
\end{tabular}

As observed in Table 2, Greek learners but not the native controls are less successful in rejecting null expletive subjects as well as in producing overt expletive forms. The case of the ADV group is very revealing: the inaccuracy rates in the expletive items are double the relevant rates in the referential items in both the PGJT and the CT. For the INT group this contrast is realized as a rise of a mean of $34 \%$ in non-target performance in the expletive items of the tasks (PGJT: $42 \%$ rise, CT: $25 \%$ rise). The BEG group in the acceptability task exhibits a performance similar with the INT group and achieves an improvement of $28 \%$ in the referential items. In the CT however, no such improvement is evinced since beginner learners are rather inaccurate (in 6 out the 10 times) in both expletive and referential items.

Postverbal subjects. Turning next to postverbal subject permutations, the analysis has shown that the variable of Group significantly differentiated performance $(p<0.05)$, and, thus all groups differed from one another. Learner performance appears improved in more advanced stages of proficiency, but what is important is that, as in the null subject items, the ADV group was significantly less accurate than the English control group. As hypothesized, advanced Greek learners allowed for structures involving postverbal subjects significantly more often than the native group did. Fig. 2 presents the relevant rates:

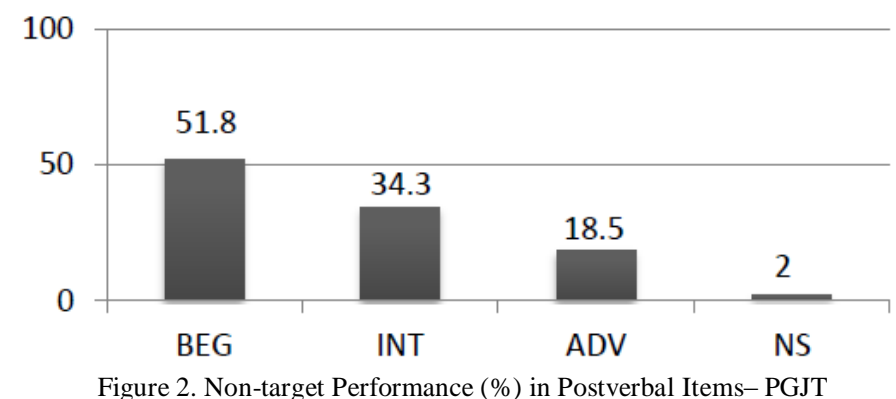


That $t$ items. As in the other item types, the analysis has returned a main effect of the variable of Group on Response in both the PGJT and the CT (both $p s<0.05$ ). As also shown by the scores on Fig. 3 below, learner performance improves with increasing proficiency; INT learners are more successful in detecting that- $t$ violations and in producing grammatical English subject extraction structures than the beginner group. However, they are not as successful as the ADV group. Interestingly and in line with what predicted, the ADV group is differentiated from the control group in that it allows and produces significantly more structures inducing that-t violations than they do.

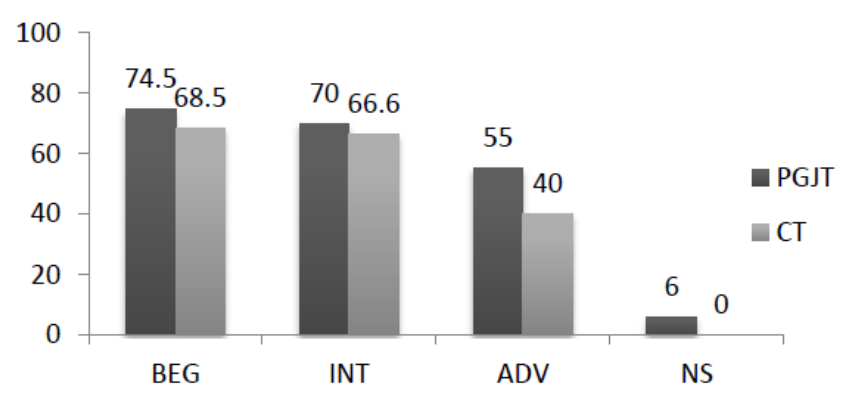

Figure 3. Non-target Performance $(\%)$ in that- $t$ violation Items- PGJT \& CT

Before closing the results section the following point needs to be made: as also evinced in other L2 studies, the participants of this experiment seem have overall lower accuracy rates in rejecting that-t violations and in producing grammatical English subject extraction structures than in rejecting postverbal and null subject configurations and in producing overt preverbal subject L2 sentences. Although a an account of that matter is beyond the scope of the present paper, it could be said that findings like the above have lead researchers to argue for a dissociation of the properties purportedly related to the NSP phenomenon (see originally Liceras, 1989 and subsequently Belletti \& Leonini, 2004; Newmeyer, 2005; Roberts \& Holmberg, 2005; Prentza, 2010; Prentza \& Tsimpli, 2013a among others).

\section{DISCUSSION}

Data from the current experiment has suggested that the L1 properties related to null and postverbal subject structures, as well as to the possibility of extracting subjects across an overt complementizer are active in the L2 grammars of Greek learners of English even at advanced levels. Within the framework adopted in the present work, the implication is that L2 abstract syntactic features associated with verbal agreement which, as previously discussed, are assumed to differ between L1 Greek and L2 English, seem inaccessible in adult L2 acquisition. L2 learners do not appear able to use formal L2 features to analyze L2 input. Hence, they resort to a transfer of the relevant L1 features, the result being that they cannot switch off the syntactic properties associated with the Greek null subject properties. This verifies our prediction regarding end-state interlanguage systems.

As for L2 development, a clear trend was reported with more proficient learners achieving more accurate performance than less proficient ones, since the intermediate group fared better than the beginner group and worse than the advanced group in all three item types across both tasks. This confirms our hypothesis concerning the improvement of L2 performance in more advanced levels. However native-like linguistic behavior was not attested even in the advanced group which was found to be significantly less successful than the English control group in all the structures tested in both the judgment and the production task.

Overall, based on the above, it can be claimed that accounts maintaining that the unsuccessful performance of L2 learners is associated with cross-linguistic differences manifested as L1 and L2 syntactic feature mismatch are supported by this work. Within this analysis, L1 transfer in the process of L2 acquisition amounts to an incorrect application of L1 syntactic properties in structures where L1 and L2 abstract syntactic features differ. On this hypothesis, interlanguage systems may differ from L1 grammars, as they differ from L2, but, nevertheless, are possible human grammars. Recent work in L2 research has suggested that L2 grammars do not replicate learner L1 grammars in the sense that notice of L2 input leads learners to adjust L1 syntactic properties. However, L2 learners continue to rely on L1 properties in order to approximate, to the extent possible, L2 forms (see Prentza \& Tsimpli, 2013a\&b; Prentza, 2010, 2013, 2014; Tsimpli \& Dimitrakopoulou, 2007).

Recently, within the realm of accounts arguing for the inhibitory role of L1 and L2 syntactic feature mismatch in the process of L2 acquisition, it has been proposed that hybrid L1/L2 interlanguage systems (i.e. systems which instantiate essentially L1 syntactic forms but on the surface appear to approximate the native norm) are achieved by the exploitation of semantic features (see Prentza \& Tsimpli, 2013a; Tsimpli \& Mastropavlou, 2007; Tsimpli \& Papadopoulou, 2009). Semantic features (like [referentiality] on nouns and pronouns) make linguistic expressions with content legible to the conceptual-international system of human cognition. In other words, semantic features are not only relevant to the syntactic computation like syntactic features are, but also carry semantic import. The differentiation of the role of syntactic and semantic features can elucidate the nature of the constraints imposed in L2 acquisition by the unavailability of the former and has proven very fruitful in advancing linguistic theory in general. 
The work presented here constitutes the pilot part of a wider study examining the acquisitional route of both formal and semantic features (for the whole study see Prentza, 2010). Although this paper largely presents only results pertaining to the possibility of acquiring formal syntactic features in L2, it is worth mentioning that the post hoc qualitative analysis of the null subject data (see Table 2) has shown that expletive null subjects which instantiate only syntactic but not semantic features appeared to be more problematic for Greek learners than referential ones. Assuming that semantic features have an alleviating role in L2 acquisition it could be said that Greek learners fare better in referential subjects because they use the semantic feature of [referentiality] to compensate for null subject overuse in Greek/English interlanguage systems (for a more detailed discussion of the issue see Prentza \& Tsimpli, 2013a). Although no statistics were performed on these results, the attested tendency supports the claim that syntactic and semantic features follow distinct acquisitional paths in the process of L2 acquisition with the former being more daily available to the L2 learners than the latter.

In sum, despite the methodological limitations inherent in any research on linguistic development, the current study examined developing and end-state interlanguage systems in an attempt to evaluate of the role of formal syntactic features in adult L2 acquisition. The obtained data raised questions as to whether properties related to syntactic features different in L1 and L2 are acquirable by adult L2 learners. Additionally, there have been indications in the present work that semantic features may be more easily accessible to adult L2 learners, and, for this reason, to be used as an alleviating strategy by L2 learners.

Closing, it must be noted that the consequences of theoretical proposals like the one adopted here are not limited to the advancement or improvement of language acquisition theories, but can also have a more functional dimension: they can be used to predict and explain areas of difficulty in foreign language learning and, consequently, teaching; they make an explicit proposal that in structures where there is a syntactic mismatch between L1 and L2, learners are expected to encounter prolonged problems. If in general the well-formedeness of a theoretical proposal is based on its power to both predict an explain the relevant observable facts, as well as to present a unified account of the various facets of the associated phenomena, then the syntactic features deficit approach which was adopted and discussed in the present study seems to qualify as such.

\section{REFERENCES}

[1] Allan, D. (1992). Oxford Placement Test. Oxford: Oxford University Press.

[2] Alexiadou, A. \& E. Anagnostopoulou (1998). Parametrizing Agr: word order, V-movement and EPP-checking. Natural Language and Linguistic Theory 16.3, 491-539.

[3] Al Kasey T. \& A.T. Pérez-Leroux. (1998). Second language acquisition of Spanish null subjects. In S. Flynn, G. Martohardjono \& W. O'Neil (eds.), The Generative Study of Second Language Acquisition. London: Lawrence Erlbaum Associates, 161-185

[4] Barbosa, P. (1995). Null Subjects. Doctoral Thesis, MIT.

[5] Barbosa, P. (2000). Clitics: a window into the null subject property. In J. Costa (ed.), Portuguese syntax: Comparative studies. New York: Oxford University Press, 31-93.

[6] Barbosa, P. (2009). Two kinds of pro. Studia Linguistica 63.1, 2-58

[7] Beck, M.L. (1998). L2 acquisition and obligatory head movement: English-speaking learners of German and the local impairment hypothesis. Studies in Second Language Acquisition 20.3, 311-48.

[8] Belletti, A., Bennati, E. \& Sorace, A. (2007). Theoretical and developmental issues in the syntax of subjects: evidence from near-native Italian. Natural Language and Linguistic Theory 25.4, 657-689

[9] Chomsky, N. (1995). The Minimalist Program. Cambridge, MA: MIT Press.

[10] Chomsky, N. (2001). Derivation by phase. In M. Kenstowicz, (ed.), Ken Hale: A life in language. Cambridge, Mass.: MIT Press, 1-52.

[11] Collins, C. (1997). Local Economy. Cambridge MA: MIT Press

[12] Collins, C. and P. Branigan. (1997): Quotative Inversion. Natural Language and Linguistic Theory 15.1, 1-41.

[13] Culicover, P. \& S. Winkler. (2008). English focus inversion. Journal of Linguistics 44.3, 625-658.

[14] Hawkins, R. \& C. Chan. (1997). The partial availability of universal grammar in second language acquisition: the 'failed functional features hypothesis'. Second Language Research 13.3, 187-226.

[15] Hawkins, R. \& H. Hattori. (2006). Interpretation of English multiple wh-questions by Japanese speakers: a missing uninterpretable feature. Second Language Research 22.3, 269-301.

[16] Kato, M. A. (1999). Strong pronouns, weak pronominals and the null subject parameter. Probus 11, 1-37.

[17] Liceras, J (1989). On some properties of the pro-drop parameter: looking for missing subjects in non-native Spanish. In S. Gass \& J. Schachter (eds.), Linguistic Perspectives on Second Language Acquisition. Cambridge: Cambridge University Press, 109133.

[18] Lozano, C. \& A. Mendikoetxea. (2010). Interface conditions on postverbal subjects: a corpus study of L2 English. Bilingualism: Language and Cognition 13.4, 475-497.

[19] Newmeyer, F. (2005). Against a Parameter-setting approach to language variation. Linguistic Variation Yearbook 4, $181-234$.

[20] Phinney, M. (1987). The pro-drop parameter in second language acquisition. In T. Roeper \& E. Williams (eds.), Parameter Setting. Dordrecht: Reidel, 221-238.

[21] Platzack, C. (2004). Agreement and the person phrase hypothesis. Working Papers in Scandinavian Syntax 73, 83-112. Lund University.

[22] Prentza, A. (2010). Feature Interpretability in Second Language Acquisition: Evidence from the Null Subject Parameter in the Greek/English Interlanguage. Unpublished doctoral Thesis, Aristotle University of Thessaloniki. 
[23] Prentza, A. (2013). Analysing the Second language Grammar of Greek Learners of English: the Phenomenon of Null Subjects. Ioannina.

[24] Prentza, A. (2014). On the problem of optionality in non-native English Subject Extraction. Journal of Greek Applied Linguistics 28, 69-89.

[25] Prentza, A. \& I.M. Tsimpli. (2013a). The Interpretability of Features in Second Language Acquisition: Evidence from Null and Postverbal Subjects in the Greek/ English Interlanguage. Journal of Greek Linguistics 13.2, 323-365.

[26] Rizzi, L. (1982). Issues in Italian Syntax. Dordrecht: Foris

[27] Prentza, A. \& I.M. Tsimpli. (2013b). On the optionality in L2 pronominal production and interpretation: what (more) can VPcoordination structures tell us? Eurosla Yearbook 13, 22-46.

[28] Rizzi, L. (1986). Null Objects in Italian and the Theory of pro. Linguistic Inquiry 17.3, 501-557.

[29] Roberts, I. \& A. Holmberg. (2005). On the role of parameters in Universal Grammar: a reply to Newmeyer. In H. Broekhuis, N. Corver, R. Huybregts, U. Kleinhentz, \& J. Koster (eds.), Organizing Grammar: Linguistic Studies in honor of Henk van Riemsdijk. Berlin \& New York: Mouton de Gruyter, 538-553

[30] Roussou, A. (2002). C, T and the subject: that-t phenomena revisited. Lingua 112.1, 13-52.

[31] Roussou, A. \& I.M. Tsimpli. (2006). On Greek VSO again! Journal of Linguistics 42.2, 317-354.

[32] Sorace, A. \& F. Filiaci. (2006). Anaphora resolution in near-native speakers of Italian. Second Language Research 22.3, 339368.

[33] Sorace, A. \& L. Serratrice. (2009). Internal and external interfaces in bilingual language development: Beyond structural overlap. International Journal of Bilingualism 13.2, 195-210.

[34] Spyropoulos, V. \& I. Philippaki-Warburton. (2001). Subject and EPP in Greek: the discontinuous subject hypothesis. Journal of Greek Linguistics 2.1, 149-186.

[35] Taraldsen, T. (1979). The theoretical implications of a class of marked extractions. In A. Belletti, L. Brandi \& L. Rizzi (eds.) Theory of markedness in generative grammar. Pisa: Scuola Normale Superiore, 475-516.

[36] Tsimpli, I.M. (1997). Resumptive features and minimalism: evidence from second language acquisition. In Proceedings of the $21^{\text {st }}$ Annual Boston University Conference on Language development. Somerville, MA: Cascadilla Press, 331-339.

[37] Tsimpli, I.M. \& M. Dimitrakopoulou. (2007). The Interpretability Hypothesis: evidence from wh-interrogatives in second language acquisition. Second Language Research 23.2, 215-242.

[38] Tsimpli, I.M. \& M. Mastropavlou. (2007). Feature interpretability in L2 acquisition and SLI: Greek clitics and determiners. In J. Liceras, H. Zobl \& H. Goodluck (eds.), The role of formal features in second language acquisition. Mahwah, NJ: Lawrence Erlbaum, 143-169.

[39] Tsimpli, I.M. \& D. Papadopoulou. (2009). Aspect and the Interpretation of Motion Verbs in L2 Greek. In N. Snape, I. Leung \& M. Sharwood Smith (eds.) Representational Deficits in SLA. Amsterdam: John Bengamins, 187-227.

[40] Tsimpli, I.M. \& A. Roussou. (1991). Parameter-Resetting in L2? In UCL Working Papers in Linguistics 3.1, 149-169.

[41] White, L. (1985). The "pro-drop" parameter in adult second language learning. Language Learning 35.1, 47-62.

[42] White, L. (1986). Implications of parametric variation for adult second language acquisition: an investigation of the pro-drop parameter. In V. Cook (ed.) Experimental Approaches to Second Language Learning. Oxford: Pergamon Press, 55-72.

[43] White, L., Montrul S., Hirakawa M., Chen D., Bruhn de Garavito, J. \& C. Brown. (1998). Zero morphology and the T/SM restriction in the L2 acquisition of psych verbs. In M.L.Beck, (ed.), Morphology and its interfaces in second language knowledge. Amsterdam: John Benjamins, 257-282.

\footnotetext{
Alexandra I. Prentza was born in Ioannina, Greece in 1978. She holds a BA in English Language and Literature from the Aristotle University of Thessaloniki, Greece (2000), an MA in Applied Linguistics from the University of Essex, United Kingdom (2002) and a Ph.D. in Linguistics from the Aristotle University of Thessaloniki, Greece (2010). In her doctoral dissertation she studied the second language acquisition of the syntactic features related to Null Subject Parameter.

For the last eight years she has been teaching English as a foreign language in the Primary School of Intercultural Education in Ioannina. The majority of her pupils are bilingual and trilingual. From 2001 to 2005 she taught English in the secondary and tertiary education as well. She also taught language development courses in the Department of Speech Therapy in the Technological Educational Institute of Epirus from 2007 up to 2011, as adjunct staff. From 2012 up to today she has been teaching in the Business Administration Department (former Department of Applied Foreign Languages in Management and in Commerce) of the Technological Educational Institute of Epirus. From 2013 she is a researcher in the BALED (Bilingual Acquisition \& Bilingual Education) programme of the Aristotle University of Thessaloniki. She has published articles on second language acquisition, second language syntax and bilingualism.
} 